Int. J. Electrochem. Sci., 14 (2019) 2833 - 2845

International Journal of

ELECTROCHEMICAL

SCIENCE

WWW.electrochemsci.org

\title{
Bacteria-immobilized Prepartion as the Microbial Probe for Electrochemical Susceptibility Test
}

\author{
Xiao Han, Lizhi Chen, Di He, Jingting He, Ye Ma, Jingjing Wang, Chang Liu* \\ College of Pharmacy, Jinzhou Medical University, No. 40, Section 3, Songpo Road, Linghe District, \\ Jinzhou City, Liaoning Province, 121001, China \\ *E-mail: liuchang@jzmu.edu.cn, hx jzmu@163.com
}

doi: $10.20964 / 2019.03 .45$

Received: 24 August 2018 / Accepted: 18 December 2018 / Published: 7 February 2019

\begin{abstract}
Electrochemical measurement of respiratory activity based on a multilayered composite of bacteria has been developed for susceptibility test. Here, we firstly report the successful fabrication of graphene oxide (GO)/polyvinyl alcohol (PVA)/Escherichia coli (E. coli)/GO/graphite rod (GR) composite, where the GO/GR composite was prepared by chemical oxidation and then the $E$. coli was confined at the surface of GO/GR composite by in site culture and crosslink of GO/PVA in sequence. Although it induced $29.07 \%$ decrease in the sensitivity of immobilized $E$. coli to toxic chemicals, the presence of GO/PVA could promote the storage stability for 20 days in term of relative bioactivity. The GO/PVA/E . coli/GO/GR composite was used as the bacterial probe in the electrochemical sensor for susceptibility test of antibiotics, and the IC50 values were determined to be $8.01 \mathrm{mg} / \mathrm{L}, 6.51 \mathrm{mg} / \mathrm{L}, 9.93 \mathrm{mg} / \mathrm{L}$ and 4.07 $\mathrm{mg} / \mathrm{L}$ for gentamicin, amikacin, amoxicillin and cefixime, which were identical with those obtained with standard Kirby-Bauer disk susceptibility (KB) testing. The vancomycin, only affecting gram-positive bacteria, exhibited an inhibition ratio of $34.5 \%$ at the concentration of $16.0 \mathrm{mg} / \mathrm{L}$ in the electrochemical susceptibility test, agreeing with the result from KB testing.
\end{abstract}

Keywords: electrochemical biosensor, nanocomposite, antibiotic efficacy testing, immobilized microorganisms, electrochemical susceptibility test.

\section{$\underline{\text { FULL TEXT }}$}

(C) 2019 The Authors. Published by ESG (www.electrochemsci.org). This article is an open access article distributed under the terms and conditions of the Creative Commons Attribution license (http://creativecommons.org/licenses/by/4.0/). 